\title{
Sujetos de derecho y cuerpos performativos. Interrogantes sobre un diseño institucional capaz de proteger a las minorías
}

\section{Subjects of law and performative bodies. Unan- swered questions about an institutional design capable of protecting minorities}

\author{
DANTE AUGUSTO PALMA \\ Universidad de Buenos Aires y Universidad de San Martín (Argentina)
}

Recibido: 06/02/2013 Aceptado: 17/06/2013

\begin{abstract}
RESUMEN
En el marco del debate acerca de los diseños institucionales capaces de dar cuenta de reivindicaciones minoritarias complejas, el siguiente trabajo se propone examinar algunas de las dificultades que se les plantean a las propuestas deconstructivistas, en particular a aquella línea teórica que realiza una crítica a la visión descriptivista del sujeto de derecho desde la perspectiva del concepto de performatividad austiniana. Así, se analizará la construcción teórica de Judith Butler, para, desde allí, marcar algunas perplejidades a las que arribaría su punto de vista y concluir, a manera de hipótesis, que un diseño institucional que pretenda una defensa de las minorías que trascienda lo meramente declamativo, no puede ni debe dejar de lado la lógica moderna que presupone, aun con una controvertida carga metafísica, la existencia de un sujeto.

PALABRAS CLAVE

PERFORMATIVIDAD, MINORÍAS, SUJETO DE DERECHO DECONSTRUCTIVISMO
\end{abstract}

\section{ABSTRACT}

In the context of the discussion about the institutional designs capable of responding to the minority complex claims, this paper intends to examine some of the difficulties that concern

(C) Contrastes. Revista Internacional de Filosofia, vol. XIX-N² (2014), pp. 249-268. ISSN: 1136-4076 Departamento de Filosofía, Universidad de Málaga, Facultad de Filosofía y Letras Campus de Teatinos, E-29071 Málaga (España) 
deconstructivist proposals, especially the theoretical line that makes a critique of the descriptivist view of the subject of law from the perspective of the concept of Austinian performativity. Thus, we analyze the theoretical construction of Judith Butler, in order to remark some perplexities attained by her views and conclude, as a hypothesis, that an institutional design which seeks the defense of minorities and transcends the merely declamatory, can't and mustn't ignore modern logic that presupposes, even with a controversial metaphysics burden, the existence of a subject.

\author{
KEY WORDS \\ PERFORMATIVITY, MINORITIES, SUBJECT OF LAW, DECONSTRUCTIVISM
}

\title{
I. INTRODUCCIÓN
}

LAS TRANSFORMACIONES CULTURALES, económicas y políticas que se sucedieron tras la caída del muro de Berlín expusieron de manera dramática la necesidad de hallar nuevas categorías con la intención de trazar una cartografía para los interrogantes que plantea el siglo XXI. De todos ellos quizás uno de los más urgentes es el vinculado a la emergencia de nuevas identidades que desafían aquellos relatos que auguraban el fin de la historia y un paulatino proceso de homogeneización que se impondría a través de los valores pretendidamente universales que traía consigo la globalización.

La problemática identitaria fue explorada directa o indirectamente por diferentes líneas teóricas entre las que se pueden entrever enfoques interdisciplinarios que conjugan elementos de la filosofía, la sociología, la ciencia política, el derecho, la antropología y la psicología. Así, la fisonomía del mundo después de 1989, por un lado, puso en la superficie la ya de por sí profusa discusión que en el ámbito anglosajón enfrentaba a liberales universalistas y comunitaristas. Los primeros pregonaban por la defensa irrestricta de los derechos individuales, (J. Rawls 1971; J. Habermas 1996, 2004) mientras que, los segundos, (A. MacIntyre 1981; M. Sandel 1982; M. Walzer, 1983; Ch. Taylor 1990) los acusaban de etnocentrismo y ofrecían herramientas para justificar que el derecho liberal debía acomodarse a las pretensiones de las comunidades en un diseño institucional capaz de acoger la noción de derechos colectivos (W. Kymlicka 1995). Se sigue de aquí que este debate acerca de la identidad estuvo y está fuertemente marcado por una perspectiva jurídica, más específicamente, por la controversia en torno al sujeto de derecho.

Sin embargo, la problemática del derecho de las minorías permitió el ingreso de una importante cantidad de exponentes del pensamiento feminista y homosexual que, frente a los movimientos liberales que exigían mera igualdad, hicieron énfasis en la necesidad de deconstruir los sujetos «mujer» $\mathrm{y}$ «heterosexual» a la vez que denunciaban el carácter hetero y androcéntrico del derecho. Buena parte de esta línea de pensamiento rechazaba las posturas 
esencialistas tanto de liberales como de comunitaristas, al tiempo que discutía los aspectos beneficiosos y contraproducentes de una total deconstrucción del sujeto (de derecho) (L. Irigaray 1974; Ch. Spivak 1977; J. Butler 1990, 1993; M. Wittig 1992; R. Braidotti 1994; D. Haraway 1995; B. Preciado 2002).

En este marco, el siguiente trabajo se propone examinar algunas de las dificultades que se les plantean a este tipo de propuestas deconstructivistas al momento de acercar diseños institucionales y jurídicos que puedan dar cuenta de la realidad efectiva de los sujetos que forman parte de estas minorías. Asimismo, dentro de las diferentes líneas teóricas deconstructivistas que critican una visión descriptivista o correspondentista del sujeto de derecho, se hará énfasis en aquella que apela a la noción de performatividad austiniana mostrando que este interesantísimo concepto no está libre de dificultades. En este sentido, se seguirá de cerca la que es, a juicio de este trabajo, la propuesta más robusta de la línea performativista, esto es, la construcción teórica de Judith Butler, para, desde allí, marcar algunas perplejidades a las que arribaría su punto de vista y concluir, a manera de hipótesis, que un diseño institucional que pretenda una defensa de las minorías que trascienda lo meramente declamativo, no puede ni debe dejar de lado la lógica moderna que presupone, aun con una controvertida carga metafísica, la existencia de un sujeto.

\section{EL PROBLEMA DE LA REFERENCIA}

Dejando de lado la extensa y riquísima discusión entre liberales y comunitaristas y las mutuas acusaciones de apoyarse en presupuestos metafísicos injustificables públicamente, algo que podría colegirse de tal debate es que las diversas posiciones discurren sobre categorías políticas de la modernidad por las cuales la posibilidad de asignación de derechos se encuentra íntimamente relacionada con la posibilidad de la afirmación de un sujeto. Dicho de otra manera, sin la presuposición de un sujeto, sea individual o colectivo, la dinámica de los derechos se transformaría en una retórica incoherente y desvinculada de lo real.

Ahora bien, decir que existe un sujeto portador de derechos implica determinar un criterio empírico de correspondencia, entre el lenguaje jurídico y el mundo. Dígase entonces que un elemento central de la discusión tiene que ver con lo que podría denominarse «problemática de la referencia» ${ }^{1}$ y podría

1 Este es el punto central que incluso puede interpretarse como uno de los núcleos de la relación que establece Foucault entre Saber y Derecho y entre Derecho y Verdad. Para observar el modo en que interactúan el discurso jurídico con otro tipo de discursos modificando y siendo modificado a su vez, ver Teubner (1997), Van Krieken (2006). Para profundizar en la impronta medicalista del derecho ver Valverde (2003). Es justamente basándose en éste que Ariza afirma «El derecho no siempre se apoya en un saber exterior. Los casos rutinarios se resuelven sin 
decirse que el liberalismo supone una «superioridad epistémica» en cuanto a que si se tiene en cuenta que los derechos individuales tienen como referencia ontológica «objetiva» el cuerpo individual, la búsqueda de una referencia empírica del grupo no puede sumir más que en la perplejidad. La razón es simple: el cuerpo individual parece ser muy efectivo como base sobre la cual depositar derechos, pero no resulta clara la entidad del grupo, ${ }^{2}$ sus límites y sus características puesto que la contrastación empírica simplemente arrojaría la existencia de una acumulación de cuerpos individuales que se dice parte de una entidad ficticia a la que denomina «grupo».

Ahora bien, expuesto así se estaría cayendo en una suerte de trampa descriptivista. En otras palabras, suponer que la lógica de los derechos se relaciona con una ontología objetiva que porta derechos naturales que esperan ser «descubiertos», es uno de los errores más frecuentes provenientes de una matriz de pensamiento histórico de un sustancialismo individualista. Sobre este punto versará este trabajo siempre teniendo en cuenta que varias de las propuestas que se siguen de la línea deconstructivista necesitan pensar un derecho que se erija sobre otro tipo de bases. En este sentido será clave indagar en el modo en que el derecho constituye la realidad y los sujetos a los cuales refiere sin que ello suponga una relación de adecuación entre enunciado y mundo. ${ }^{3}$ Tal indagación

necesidad de producir «verdad» y sin apoyarse en un conocimiento pleno» (L. Ariza 2009, p. 57). Por último, para comprender mejor la utilización del saber antropológico aplicado a un caso ver Clifford (1995) y Ariza (2009).

2 Sobre este punto es interesante la postura de Butler que puede pensarse en diálogo con Laclau acerca del uso de los universales en política. Para la autora de El género en disputa, las categorías de identidad no son descriptivas sino normativas de lo cual se siguen que acaban generando exclusión. En otras palabras, el intento universalizador del colectivo mujer encierra una faccionalización que acaba imponiendo el criterio falsamente descriptivo que aparentemente es el distintivo del colectivo. En palabras de Butler: «En el momento en que la categoría de mujeres se invoca para «describir» al electorado por el que habla el feminismo, comienza invariablemente un debate acerca de lo que será el contenido descriptivo de ese término [...] Pero cada vez que se formula esa especificidad, existe resistencia y faccionalización dentro del mismo electorado que se supone que debe ser «unificado» por su elemento común. [...] Yo argumentaría que cualquier esfuerzo por darle un contenido universal o específico a la categoría de las mujeres, presumiendo que esa garantía de solidaridad se requiera por «anticipado», necesariamente producirá faccionalización, y esa «identidad» como punto de partida nunca se podrá sostener como la base solidificadora de un movimiento político feminista» (J. Butler 1992, pp. 32-33)

3 Es muy interesante la forma en que Ariza aplica la noción de performatividad al caso de la constitución de la identidad indígena en Colombia desde el momento de la colonización hasta la reforma constitucional del 91 en la que se reconoce jurídicamente a las diversas comunidades. «Lejos de representar un reconocimiento -falso o auténtico- de la alteridad, el proceso de dominación colonial y poscolonial supone la creación -o invención, si se quiere-de una alteridad que se acomode, justifique o responda a los procesos sociales, políticos y económicos en marcha [...] El sujeto jurídico es el resultado de una maquinaria jurídica que recibe como insumo un saber 
será un elemento central para pensar una teoría no representacionalista de la identidad y los derechos.

Para poder quebrar, entonces, la matriz del pensamiento representacional propia de los sistemas jurídicos occidentales y transitar los senderos que pudieran abrirse en torno a la protección de las minorías, cabe profundizar aquí en una teoría que, especialmente a partir de los años 90, ha llevado al feminismo y a pensadores neomarxistas como Virno (2004) o neofoucaulteanos como Lazzarato (2006b), a repensar una noción cara al pensamiento anglosajón. Se trata, pues, del inmenso punto de inflexión que produjo la noción de acto performativo (o realizativo) que Austin desarrollara en las conferencias que fueron publicadas en 1962 con el sugestivo nombre de Hacer cosas con palabras. ${ }^{4}$ Referida al campo de lo político, la idea de performatividad permite pensar la acción política, la libertad y la novedad por fuera de los puntos de vista más esquemáticos que suponen los esencialismos liberales y comunitaristas como así también el marxismo clásico preso de categorías tales como conciencia y clase. Las razones por la que tal noción pudo ser resignificada por tradiciones tan diversas son complejas pero sin duda pone de manifiesto que, tras el giro lingüístico, parece difícil volver a pensar la política y la constitución de la subjetividad independientemente de la problemática del lenguaje. ${ }^{5}$

\section{ORIGEN Y PRESUPUESTOS DE LA NOCIÓN DE PERFORMATIVO}

En las conferencias antes mencionadas, Austin realiza una distinción que será clave para aquellos que intentan arremeter contra la noción representacional que fue el centro del pensamiento moderno. El eje central gira en torno a la afrenta que Austin realiza al pensamiento paradigmático del neopositivismo que tiene en «el primer» Wittgenstein a uno de sus mayores exponentes. ${ }^{6} \mathrm{Se}$

sobre la alteridad y que, a cambio, emite un discurso sobre los rasgos que constituyen al sujeto que considera como el auténtico destinatario de las normas jurídicas» (L. Ariza 2009, pp. 55-56).

4 Además de los que se mencionarán a continuación, algunas referencias interesantes acerca de la noción de lo performativo se las puede hallar en Searle, (1969); Pratt (1977); Johnson (1980) y Felman (1983).

5 Asimismo, cabe mencionar el modo en que una disquisición aparentemente técnica y académica como la propuesta de Austin, resulta altamente significativa para las problemáticas cotidianas de sociedades complejas y multiculturales. Por mencionar sólo un caso, en la Argentina, el Instituto Nacional contra la discriminación (INADI), lleva adelante una política pública de generación de conciencia antidiscriminatoria basada en la noción de la performatividad del lenguaje. En esta línea, se entiende que las formas de segregación parten y son instituidas por el lenguaje mismo de modo que parece preciso desnaturalizar apodos, sobrenombres o formas de identificación despectivas para comenzar un cambio cultural que promueva mayor respeto por la diferencia.

6 Es interesante aquel comentario de Searle acerca de la distinción entre dos perspectivas 
trata de la afirmación de que sólo tienen sentido aquellos enunciados que describen un estado de cosas y que, por lo tanto, son pasibles de ser verdaderos o falsos. Estos enunciados que Austin llamará «constatativos» deben distinguirse de otro tipo de enunciados que este profesor de Oxford llama realizativos (o performativos) y que se caracterizan por ser aquellos cuya mera enunciación, en determinadas circunstancias, supone la realización de un acto distinto al acto de enunciar. Son ejemplos paradigmáticos en este sentido una promesa, un juramento o la sentencia dictada por un juez.

La forma más común de este tipo de enunciaciones lleva en el plano gramatical la forma de un verbo en la primera persona del singular del presente indicativo, voz activa. Así, una promesa podría formularse del siguiente modo: «Prometo que te voy a dar el regalo de cumpleaños el lunes».

Las primeras conferencias compiladas en este libro problematizan el criterio a partir del cual es posible evaluar una expresión realizativa puesto que, aparentemente, predicar de ellas una verdad o una falsedad parece impropio. Así, Austin trata de establecer en qué sentido un enunciado realizativo puede ser desafortunado, esto es, no desarrollarse en el contexto de las circunstancias apropiadas. Decir «yo los declaro marido y mujer» sin ser juez, o habiendo una sola persona delante, etc., supone uno de los casos en los que el marco de la acción en el que se pretende realizar la enunciación, falla.

Las conferencias subsiguientes vuelven a la cuestión de la necesidad de trazar una distinción entre enunciados descriptivos y performativos, desarrollo que lleva casi a la perplejidad a Austin puesto que muestra que la diferencia que parecía tan tajante no es tal y que los realizativos no pueden prescindir completamente de alguna conexión con lo verdadero, tanto como los constatativos deben cumplir con el requisito de ser «afortunados».

En este contexto es que Austin se repregunta qué se quiere decir cuando se afirma que existen enunciaciones que suponen la realización de un acto distinto del acto de enunciación. Es en este punto que Austin desarrolla la ya clásica distinción de las dimensiones del acto de habla. En otras palabras, en el acto de enunciar se halla una dimensión locucionaria, una ilocucionaria y una perlocucionaria. En lo que respecta a la dimensión locucionaria se trata del acto de emitir sonidos que pertenezcan a cierto vocabulario respetando determinado orden y con algún sentido. En cuanto a la dimensión ilocucionaria ${ }^{7}$

no incompatibles dentro de la filosofía del lenguaje: la que se ocupa de las expresiones del habla y la que se ocupa del significado de las oraciones. Si a Searle y a Austin se los ubica en el primer grupo, sin dudas, al «primer» Wittgenstein, esto es, el del Tractatus, se lo ubica en el segundo. Para profundizar en este punto ver Searle (1969, cap. 1).

7 La dimensión ilocucionaria es la que más le interesa a Searle y en su Actos de Habla, hace una lista de los verbos en castellano que suponen actos ilocucionarios. Allí menciona «enunciar», «describir», «aseverar», «aconsejar», «observar», «comentar», «mandar», «ordenar», 
del acto, se trata del acto que se lleva a cabo al decir algo, esto es, el acto de prometer, felicitar,amenazar, etc.. ${ }^{8}$ Y por último, la dimensión perlocucionaria, se identifica con aquel acto que se provoca en el otro, por ejemplo, conformar, reflexionar, etc. ${ }^{9}$

Si bien no es éste el espacio para problematizar las críticas que recibiese la propuesta austiniana, sí se mencionará la que efectuara Jacques Derrida (1971) pues será relevante para comprender el modo en que Judith Butler utiliza la

«pedir», «criticar», «pedir disculpas», «censurar», «aprobar», «dar la bienvenida», «prometer», «objetar», «solicitar», «argumentar». Más allá de que excede este trabajo, cabe mencionar que el propio Searle duda de la distinción austiniana entre actos locucionarios e ilocucionarios. Ver Searle (1969, cap 1).

8 Para un interesante desarrollo acerca de las normas jurídicas entendidas como actos ilocutivos, ver López Hernández (2005).

9 Más allá de que excede este trabajo, cabe mencionar, por ejemplo, la utilización que hace un pensador marxista y materialista como Paolo Virno, de la noción de performatividad. El pensador italiano en Cuando el verbo se hace carne (2004), dedica buena parte de su libro a criticar a los que afirman que el lenguaje es un mero instrumento del conocimiento, una suerte de exterioridad de la cual se serviría el humano. En este sentido, construye una teoría acerca de la naturaleza humana que supone que el Hombre es esencialmente, un animal político, es decir, un animal de lenguaje. Así, quien habla, al igual que un artista cuando actúa, realiza una acción en sí misma, independientemente de la finalidad de alcanzar o legar determinado objeto. En este sentido, Virno afirma que el hablar, el ver y el respirar son acciones que manifiestan el modo de ser de un determinado organismo biológico. Esto significa que la acción de hablar, al igual que como sucede con las acciones del ver o del respirar, no se realizaría por razones ventajosas. Son acciones que simplemente se realizan y son autorreferenciales. La erudición de Virno lo lleva incluso a Metafísica de Aristóteles para encontrar allí los modos en que la discusión acerca de la potencia y el acto arrojan casos en el que la finalidad es el ejercicio mismo de una facultad y no necesariamente la producción de un objeto distinto de la facultad misma. Así, en la línea de pensadoras como Butler, la noción de performativo es utilizada por Virno dada las posibilidades prácticas que supone, a tal punto que el pensador italiano entiende que una de las características de este tipo de enunciados es que permite realizar un acto sin referencia alguna o línea causal. Es por eso que quien toma la palabra está dando inicio a un evento único e irrepetible, algo que se verá a continuación cuando ingresen categorías derridianas útiles para el pensamiento de Butler. Pero Virno intenta ir bastante más allá para poder afirmar la existencia de lo que él denomina el «performativo absoluto», cuya única forma es el «yo hablo». Este «yo hablo» es anterior a cualquier acto performativo y manifiesta la supremacía del acto por sobre el contenido de lo que se dice. Se trata de resaltar la potencialidad humana en tanto capacidad de poder decir. Asimismo este performativo anómalo, en términos del propio Virno, es incapaz de ser desafortunado porque no depende del contexto histórico-institucional en el que se formule. En este sentido, la afirmación «Yo hablo» nunca puede estar viciada pues su mera enunciación supone el cumplimiento de la acción. Sobre esta base, Virno retomará la problemática de la multitud, la individuación y las posibilidades que un pensamiento neomarxista tiene hoy para afectar las condiciones de las nuevas formas del capitalismo. 
idea de lo performativo como estrategia de resignificación del sujeto Mujer por fuera de la lógica falogocéntrica.

En «Firma, acontecimiento, contexto», Derrida parte de la crítica a una definición de comunicación como el lugar de paso de un único sentido claramente definible. Sobre esta base, el nacido en Argelia, trabajará la problemática de la escritura para mostrar que la definición, antes indicada, de comunicación, posee una serie de presupuestos inadmisibles. Más específicamente, Derrida señala que la idea de performatividad de Austin se sustenta en una base que considera que es posible definir con claridad y univocidad los contextos en los cuales los actos performativos tienen lugar. ${ }^{10}$ Asimismo, Derrida señala que estrechamente vinculada a esta suposición de un contexto claramente determinable, está la trampa del lenguaje a la que Austin no pudo escapar, esto es, una metafísica de la presencia, de la conciencia y de la intención. En términos de Derrida, la noción de performatividad de Austin supone, entonces, un sujeto previo al acto lingüístico con una determinada voluntad que según el contexto logrará que ese acto performativo sea o no eficaz.

Los análisis de Austin exigen un valor de contexto en permanencia, e incluso de contexto exhaustivamente determinable, directa o teleológicamente; y la larga lista de fracasos (infelicities) de tipo variable que pueden afectar al acontecimiento del performativo viene a ser un elemento de lo que Austin llama el contexto total siempre. Uno de estos elementos esenciales -y no uno entre otros- sigue siendo clásicamente la conciencia, la presencia consciente de la intención del sujeto hablante con respecto a la totalidad de su acto locutorio. Por ello, la comunicación performativa vuelve a ser comunicación de un sentido intencional, incluso si ese sentido no tiene referente en la forma de una cosa o un estado de cosas anterior o exterior (J. Derrida 1971, pp. 363-364). ${ }^{11}$

10 El elemento contextual, la dimensión social, es central en el performativo a punto tal que un pensador como Lazzarato (2006b) lo destaca para estructurar su propio punto de vista y a su vez distinguirse del de Virno. Para Lazzarato, el performativo absoluto de Virno, el «Yo hablo», no tiene en cuenta la verdadera potencia del performativo, esto es, la obligación social que genera y, con ello, su fuerza creadora y transformadora. El «yo hablo» no necesita de un otro. Es por eso que Lazzarato propone un punto de vista dialógico, el cual, a su vez, es visto desde la perspectiva del poder foucaultiana, que entiende que éste no es una relación de dominación sino que tiene como objeto una relación que es, por definición, reversible y móvil. En este sentido retoma a Bajtin para mostrar que en los actos de habla el interlocutor participa activamente, determinando en parte la dinámica, y que todo acto de enunciación entra en un terreno de poder en el que indefectiblemente hay resistencias y no una imposición unilateral.

11 Podría decirse que Lazzarato (2006a) se monta sobre tal crítica para atacar también a Butler. Como se verá más adelante, la suposición de la existencia previa de contextos dados encierra a la performatividad en un margen de maniobra escaso incapaz de quebrar lo dado. De aquí que el italiano considere necesario ir un paso más allá y pensar la acción política como un acontecimiento que irrumpe, establece una verdadera novedad y no es parte de una intencional teleología emancipadora. 
Dicho esto, Derrida toma el ejemplo de la escritura elaborando una teoría que será muy útil a Butler. Se trata de mostrar que una de las particularidades de la escritura es que funciona en ausencia de su emisor y de su destinatario. Esto significa que lo esencial de la escritura es su posibilidad de ser repetible en el sentido de que sólo así funcionará independientemente de la presencia. Esta capacidad de repetición es la que Derrida llama el carácter iterable de la escritura, lo cual significa que no es una mera repetición de un signo sino una repetición que siempre supone un «iter», un otro, una alteridad. De aquí que ninguna repetición sea igual a la otra pues siempre incluye un «resto» algo que no estaba presente anteriormente. Esto se vincula claramente con la cuestión del contexto antes mencionado pues el signo escrito tiene una materialidad, una marca que le permite exceder largamente el contexto en el que fue creado y hace que pueda ser injertado en un contexto distinto que, en tanto tal, supone una modificación del sentido que tuvo aquel signo en su origen.

Este potencial de repetición infinita es lo que Derrida también llama «citabilidad del signo», esto es, la posibilidad de poder ser citado y, por ello mismo, ser descontextualizado.

Todo signo, lingüístico o no lingüístico, hablado o escrito (en el sentido ordinario de oposición), en una unidad pequeña o grande, puede ser citado, puesto entre comillas; por ello puede romper con todo contexto dado, engendrar al infinito nuevos contextos, de manera absolutamente no saturable. Esto no supone que la marca valga fuera de contexto, sino al contrario, que no hay más que contextos sin ningún centro de anclaje absoluto (J. Derrida 1971, pp. 361-362).

De este modo, Derrida concluye que la presencia, la conciencia y el acto de habla no son más que efectos a ser analizados y que de ninguna manera se puede pensar en voluntades e intencionalidades claramente determinables. Esta es la base que le será útil a Butler pues ella intentará construir una estrategia feminista que evite caer en las posiciones extremas del feminismo de la diferencia sexual que presupone un sujeto mujer perfectamente identificable, y del constructivismo lingüístico que afirma que lo real está determinado de manera absoluta por el lenguaje.

\section{JUDITH BUtLER Y LA PERFORMATIVIDAD COMO ESTRATEGIA}

Butler retoma la idea de performatividad atravesada por la advertencia derridiana y por el pensamiento de Foucault. Especialmente con este último, a Butler le interesa aplicar la noción de lo performativo a su punto de vista de la problemática del feminismo. ${ }^{12}$ Para la autora de Deshacer el género, la

12 «Butler hace una lectura postestructuralista de la teoría de los actos de habla, atravesada fundamentalmente, por el discurso derrideano. En consecuencia, el aporte de Austin habría 
distinción entre un cuerpo biológico y un género cultural es funcional a la objetivación patriarcal. Así, lo que se entiende por cuerpo no es un dato natural sino también una construcción cultural de lo cual se sigue que no tiene sentido distinguirlo de la noción de género. ${ }^{13}$ La estructura lógica binaria del pensamiento occidental y patriarcal es la que performativamente ha determinado los sujetos a los cuales refiere. El cuerpo no estaba ahí esperando ser nombrado sino que por haber sido nombrado «apareció» ahí.

De este modo, Butler sigue a Foucault en cuanto a la centralidad que le otorga al plano discursivo como aquel que provee los significantes que determinan lo real. Desde esta perspectiva, el lenguaje configura la realidad y el lenguaje de la política y el derecho configuran los sujetos a los cuales refieren. La postura de Butler, entonces, realiza una genealogía para desenmarañar una red naturalizada que presenta a la política y al derecho como legítimos emergentes de la necesidad de unos sujetos preexistentes. No hay sujeto, ni conciencia ni voluntad reclamando ser reconocida como sujeto de derecho. ${ }^{14}$

Foucault afirma que los sistemas jurídicos de poder producen a los sujetos jurídicos a los que más tarde representan. [...] Los campos de representación lingüística y política definieron con anterioridad el criterio mediante el cual se originan los sujetos mismos y la consecuencia es que la representación se extiende únicamente a lo que puede reconocerse como un sujeto. Dicho de otra forma, deben cumplirse

consistido, para el postestructuralismo, en una incipiente ruptura con la teoría representativa del significado; ya que, para la teoría de los actos de habla, comunicar no sería «transmitir»o «hacer presente» una idea previa, sino una fuerza performativa que no existe con anterioridad a la emisión de una forma verbal en determinadas condiciones» (F. Boccardi 2010, p. 26)

13 Asimismo, hay en Butler una crítica a los discursos románticos de los esencialismos del sexo no tanto porque pongan a la sexualidad como variable privilegiada de identificación sino porque sostienen que la liberación está en el reencuentro con esa sexualidad originaria perdida. En palabras de Foucault: «El sexo, esa instancia que parece dominarnos y ese secreto que nos parece subyacente en todo lo que somos, ese punto que nos fascina por el poder que manifiesta y el sentido que esconde, al que pedimos que revele lo que somos y nos libere de lo que nos define, el sexo, sin duda, no es sino un punto ideal hecho necesario por el dispositivo de sexualidad y su funcionamiento. No hay que imaginar una instancia autónoma del sexo que produjese secundariamente los múltiples efectos de la sexualidad a lo largo de la superficie de contacto con el poder. El sexo, por el contrario, es el elemento más especulativo, más ideal, y también más interior en un dispositivo de sexualidad que el poder organiza en su apoderamiento de los cuerpos, su materialidad, sus fuerzas, sus energías, sus sensaciones, sus placeres», (M. Foucault 1976, pp. 147-148).

14 Tomando, por ejemplo, la línea liberal de la tradición contractualista, los sistemas jurídicos buscan positivizar una serie de derechos naturales que son poseídos desde un principio por los individuos. Esta misma idea es la que sostiene la política de Derechos Humanos al afirmar que todo hombre independientemente del tiempo y el espacio en que le toca vivir posee una serie de derechos que no pueden ser vulnerados. 
los requisitos para ser un sujeto antes de que pueda extenderse la representación [...]. El problema del sujeto es fundamental para la política y concretamente para la formación feminista, porque los sujetos jurídicos siempre se construyen mediante ciertas prácticas excluyentes que, una vez determinada la estructura de la política, no se perciben (J. Butler 1999, pp. 46-47).

El acento en la performatividad de un lenguaje creador de sus propios referentes aparece también en Haar, quien retoma de Nietzsche la crítica a la metafísica de occidente y a las consecuentes ficciones sustantivistas que reproduce la gramática:

Todas las categorías psicológicas (el yo, el individuo, la persona) proceden de la ilusión de identidad sustancial. Pero esta ilusión regresa básicamente a una superstición que engaña no sólo al sentido común, sino también a los filósofos, es decir, la creencia en el lenguaje y, más concretamente, en la verdad de las categorías gramaticales. La gramática (la estructura del sujeto y el predicado) sugirió la certeza de Descartes de que el «yo» es el sujeto de «pienso» cuando más bien son los pensamientos los que vienen a «mí»; en el fondo la fe en la gramática sólo comunica la voluntad de ser la causa de los pensamiento propios. El sujeto, el yo, el individuo son tan sólo falsos conceptos, pues convierten las unidades ficticias en sustancias cuyo origen es exclusivamente una realidad lingüística (M. Haar, 1977, pp. 17-18).

Esta idea de «sujeto a posteriori» de la política y el derecho se traslada tanto contra la versión liberal como la colectivista. En otras palabras, hay ficción en la idea de un sujeto colectivo pero también hay ficción en la idea de un sujeto individual puesto que el cuerpo no es otra cosa que una materialidad simbólica en la cual se inscribe el lenguaje del derecho. Para dar cuenta de esto, Butler utiliza a Foucault especialmente en su análisis del caso del hermafrodita Herculine. Este punto es interesante porque arremete contra el cuerpo sexuado y su naturalización basada en la aparente objetividad de las diferencias morfológicas. En esta línea, Butler y Foucault denuncian también la operación de construcción del género y el sexo, y el carácter performativo de estas nociones.

A partir de su interpretación sumaria de Herculine, Foucault propone una ontología de atributos accidentales que muestra que la demanda de identidad es un principio culturalmente limitado de orden y jerarquía, una ficción reguladora (J. Butler 1999, p. 78).

Este énfasis en el carácter construido del cuerpo es aquel en el que Butler hace especial hincapié en un libro posterior al Género en disputa cuyo título resulta bastante elocuente: Cuerpos que importan (1993). 
Allí Butler se encarga de profundizar la idea de que lo performativo es claramente extensible a la materialidad del cuerpo: no hay una morfología ontológicamente privilegiada del sujeto mujer sino que el cuerpo femenino es el efecto de una continua repetición de normas que, a través de los discursos epocales, ${ }^{15}$ ha sedimentado un conjunto de signos de los cuales se ha olvidado su origen.

La autoridad se constituye haciendo retroceder infinitamente su origen hasta un pasado irrecuperable. Este diferimiento es el acto repetido mediante el cual se obtiene legitimación. La referencia a una base que nunca se recobra llega a constituir el fundamento sin fundamento de la autoridad (J. Butler 1993, p. 164).

Sin embargo, presentado así, Butler no diferiría de las teóricas constructivistas que piensan el lenguaje como un determinante total de lo real. Según el punto de vista de este trabajo, es con la intención de salir de la incomodidad del presunto nihilismo al cual llevaría la postura constructivista, que Butler ensaya una argumentación compleja para afirmar que existe una materialidad independiente del lenguaje pero que esta materialidad no supone una ontología privilegiada que permita justificar objetivamente la diferencia entre los sexos. Por qué Butler elige este sendero argumentativo es una incógnita pero una de las razones podría estar vinculada a la dificultad que se les plantea a varios pensadores neomarxistas una vez que asimilan que ya no es posible pensar que el sujeto revolucionario del siglo XXI pueda rastrearse en la clase proletaria. De hecho, esta parece ser la preocupación de autores como Hardt y Negri (2000), Zizek (2003), Laclau (2003, 2005) o Mouffe (2007). En el caso de Butler se trata de un pensamiento que obviamente no busca revitalizar el sujeto femenino tal como fue concebido originalmente allá por los años cincuenta. Más bien,

15 A la luz de esto podría leerse la actividad militante de la propia Butler denunciando los diferentes tipos de discursos que actúan performativamente sobre los sujetos a los cuales refiere. Por mencionar un ejemplo, en la línea de la aclaración que se hacía algunas líneas atrás respecto de las políticas públicas llevadas adelante por el Instituto contra la discriminación en Argentina, a mediados de la década del 90, Butler publica un artículo en el que encara la problemática de los «discursos del odio», en el contexto de una discusión pública acerca de una ley que prohibía manifestaciones verbales discriminatorias. «Las recientes propuestas de regular el discursos del odio en los campus, los lugares de trabajo y otros espacios públicos han tenido una serie de consecuencias políticas ambivalentes. La esfera del lenguaje se ha convertido en el dominio privilegiado para interrogar las causas y efectos de la ofensa social. Mientras que en momentos tempranos del movimiento de los derechos civiles o en el activismo feminista lo que se primaba era documentar y buscar resarcimiento frente a varias formas de discriminación, la actual preocupación política por el discurso del odio enfatiza la forma lingüística que asume una conducta discriminatoria, por el procedimiento de tratar de establecer la conducta verbal como acción discriminatoria» (J. Butler 1997, p. 1). 
su intención es encontrar dentro del pensamiento feminista un espacio para lo otro, esos seres cuyo cuerpo y objeto de deseo no es el convencional. Esto no es otra cosa que lo Butler llama los «cuerpos abyectos», esto es, los cuerpos de los transexuales, las travestis, los «malformados», y de aquellos cuyo objeto de deseo se desvía de la norma heterosexual. ${ }^{16}$

Ahora bien, Butler no ahorra argumentaciones eclécticas para justificar que en estos grupos está la posibilidad de cambiar el orden de cosas. Para ello recurre, como muchos de los autores mencionados, no sólo a los elementos ya indicados de Foucault y de Derrida, sino a los grandes pensadores de la semiótica y, particularmente, al psicoanálisis lacaniano.

Si bien no se desarrollarán en profundidad estos presupuestos debe aclararse que, con Lacan, Butler muestra que todo discurso, para dar inteligibilidad, necesita de un exterior constitutivo. En este sentido no son pocos los análisis que en política muestran que no hay «nosotros» sin un «ellos». El punto es que aquello que queda afuera es, para Butler, algo innombrable, ininteligible, de aquí que ella se sirva de la categoría lacaniana de lo Real como aquel espacio que no puede ser puesto en palabras. Es en este punto donde Butler dice sortear el problema del constructivismo radical pues ella indica que ese afuera innombrable e ininteligible posee una materialidad que, si bien resulta «indescifrable» a los ojos de este discurso que constitutivamente la arrojó más allá, existe. Eso que está por fuera del discurso y del lenguaje es, justamente, la materialidad de los cuerpos abyectos que en tanto límite exterior siempre está en una relación de tensión fronteriza con ese interior.

\section{LIBERAR DESDE LA NORMA: LA PARADOJA DE LA SUJECIÓN}

Habiendo llegado aquí, cabe mencionar alguna de las problematizaciones que introduce Butler, muchas de las cuales tendrán consecuencias en los desarrollos posteriores.

El primer punto que se puede señalar es el que ella denomina «paradoja de la sujeción» (J. Butler 1993) y que abre un interrogante acerca de cuál es la estrategia de emancipación adecuada para el feminismo. La paradoja se produce puesto que si se considera que, siguiendo a Foucault, la matriz de los discursos

16 Independientemente de si este punto de vista de Butler es correcto o no, se encuentra aquí un elemento que Lazzarato parece pasar por alto en su crítica. Para el italiano, Butler es una constructivista que olvida la necesidad de una materialidad exterior a la lengua. En esta línea, Lazzarato considera que el performativo de Butler no toma en consideración las resistencias materiales que le pueden aparecer a la suposición omnipotente del performativo. «Tanto Virno como Butler, aunque sea de modos diferentes, cierran la enunciación sobre la lengua, como si la lengua pudiera tenerse en pie sobre ella misma; secretar, a través de estructuras sintácticas, fonéticas o gramaticales, las significaciones; engendrar la potencia de actuar sobre los demás y explicar la fuerza de transformación del lenguaje y los signos» (M. Lazzarato, 2006a, p. 21). 
históricos es la que constituye y a la vez brinda la condición de posibilidad de los sujetos, cualquier estrategia liberadora depende de este constructo generado a partir de las normas que se intenta subvertir. La perplejidad radicaría en preguntarse si el discurso de la separación binaria de los sexos admite una estrategia rupturista que permita irrumpir lo nuevo.

Esta paradoja del sujeto por el cual su posibilidad de des-sujeción depende de la misma normativa que lo sujetó, tiene obviamente consecuencias importantes a la hora de pensar la identidad y las estrategias minoritarias.

Lo interesante es que esto supone la aceptación de que toda disputa acerca de la identidad se hace sobre la base de cierta normatividad histórica constitutiva de lo cual se sigue, aunque parezca una obviedad, que la deconstrucción se hace siempre sobre lo construido. En términos más precisos, la diferencia sexual es falsa descriptivamente, pero su instauración a través de la lógica performativa del discurso es un dato ineludible. Todo intento de transformación, debe partir de esa base.

Esto es claramente reconocido por Butler cuando afirma:

El 'sexo' siempre se produce con una reiteración de normas hegemónicas. Esta reiteración productiva puede interpretarse como una especie de performatividad. La performatividad discursiva parece producir lo que nombra, hacer realidad su propio referente, nombrar y hacer, nombrar y producir. Paradójicamente, sin embargo, esta capacidad productiva del discurso es derivativa, es una forma de iterabilidad o rearticulación cultural, una práctica de resignificación, no una creación ex nihilo. (J. Butler 1993, pp. 162-163).

Se sigue de aquí que Butler debe recurrir a la noción de iterabilidad derridiana para poder justificar que si bien las condiciones históricas hacen que la emancipación deba provenir de este sujeto ficcional que construyó el discurso moderno, es posible, desde allí, establecer una estrategia de desestabilización de la norma. Esto tiene que ver con que para Butler, el aspecto ilocutivo no se instaura en un acto único. Así, como forma de denuncia a aquella diferencia sexual que no es más que el sedimento cristalizado de una inmensa cantidad de repeticiones, Butler propone pensar el ser del sujeto como un verbo y no como un sustantivo pues es el lenguaje el que obliga a pensar en términos de sustancia. Dicho esto, la propuesta de Butler pasa por una acción que se torne repetición paródica: realizar una performance, «actuar» el género, «actuar»el sexo como una parodia, reapropiarse de los significantes para resignificarlos. Esto sólo puede ser posible una vez que Butler hace suya la noción derridiana de iterabilidad, esto es: las repeticiones nunca son repeticiones de lo mismo puesto que cada intento de actuar lo mismo aporta una diferencia que hace 
que todo acto sea irrepetible. ${ }^{17}$ Esta «pequeña» diferencia, que no supone una jerarquía propia del pensamiento platónico del modelo y la copia, es la que en sucesivas repeticiones puede aportar un cambio «sustancial» y es lo que puede operar como un acto, a la larga, liberador y transformador. ${ }^{18}$ Esta idea es similar a la expuesta por Borges en «Pierre Menard, autor del Quijote», donde el personaje del cuento se propone transcribir el texto de Cervantes palabra por palabra sin incurrir en un plagio, algo que sólo resulta posible en la medida en que se concibe que una obra nunca está terminada sino que recibe continuas resignificaciones según el lector de cada época. Pierre Menard, parece así un candidato a ser el sujeto de la subversión paródica de Butler. Alguien que hace lo mismo pero diferente y donde no hay más que contextos sin sujetos. ${ }^{19}$

\section{LA PROTECCIÓN EN EL MIENTRAS TANTO DE LA PARODIA}

Como se indicó a lo largo de este trabajo, la noción de performatividad tal como fue planteada originalmente por Austin ha sufrido una serie de críticas que han puesto énfasis especialmente en aquellos presupuestos modernos, esas trampas del lenguaje que llevan a considerar que detrás de todo acto hay un sujeto, una conciencia y una voluntad. Esto fue especialmente lo que señaló Derrida y que resultó central para la interesante propuesta de Butler en torno a las posibilidades que lo performativo puede tener para una estrategia emancipatoria contra la matriz heterosexual.

Sin embargo, hay en Butler un interés explícito en desembarazarse de los dos extremos del debate al interior del feminismo, esto es, la corriente que presenta que hay un aspecto distintivo de la mujer fundado en la especificidad objetiva de las diferencias morfológicas, y la tradición del constructivismo

17 La noción de iterabilidad le sirve a Butler para reflexionar también acerca de los discursos del odio racistas y para encarar la performatividad del discurso de la pornografía que acaba subordinando a las mujeres y el cual, como todo discurso discriminatorio, estaría avalado por la no sanción por parte del Estado. Para profundizar sobre la controversia en torno al discurso de la pornografía y el modo en que afecta a sus destinatarios, ver Mac Kinnon (1993) y Butler (1997). También resulta interesante ver la disputa que se dio entre la propuesta de censurar la pornografía que tomó forma en el proyecto presentado por MacKinnon y Andrea Dworkin, y los contraargumentos esgrimidos al respecto por Ronald Dworkin (1996).

18 Butler entiende que la utilización de la iterabilidad derrideana la distingue del punto de vista de Foucault: «Foucault caracteriza la ley lacaniana como performativa jurídica: «habla y esa es la norma»; esta ley es «monótona y está aparentemente condenada a repetirse». Aquí Foucault supone que esta repetición es una repetición de aquello que es idéntico a sí mismo. De modo que Foucault entiende que las acciones performativas y repetitivas de la ley lacaniana producen sujetos uniformes y homogéneos; los sujetos normalizados de la represión» (J. Butler 1993, p. 48).

19 Para profundizar las implicancias de este cuento de Borges, remitirse a Palma (2010, cap. 3). 
lingüístico radical que indica que no existe ninguna materialidad independiente del lenguaje.

Fue así que Butler, en la búsqueda del «sujeto» que pueda subvertir el orden, se sirvió de la noción lacaniana del afuera innombrable y constitutivo de todo discurso para depositar allí a esos cuerpos abyectos que desde la frontera buscarán desestabilizar lo dado.

El punto aquí es, ya que Butler evidentemente está pensando en una teoría con fines prácticos anclada en el horizonte más o menos preciso del siglo XXI, cómo podría llevarse adelante esta irrupción de lo abyecto. De hecho, recuérdese que existe un claro reconocimiento de que todo intento transformador debe partir de la base sedimentada de signos de un discurso jurídico para el cual resulta imposible poder pensar sin remitirse a una noción de agencia, responsabilidad y sujeto. De esta manera, la repetición paródica con el fin de dar nuevos sentidos no parece alcanzar para explicar la forma en que el derecho podría acoger esta novedad. Si bien resulta claro que Butler, como buena parte del pensamiento feminista, denuncia al derecho en tanto reproduciría la lógica patriarcal y heterosexista, resulta de un nivel de abstracción imperdonable soslayar lo que sucedería en el mientras tanto de las repeticiones paródicas. En otras palabras: ¿qué tipo de protección tendrían estos cuerpos ininteligibles? Aun tomando en cuenta el ejemplo de Herculine en el que se mostró que la norma produce y obliga a los cuerpos a que se acomoden a ella, con todo, existen protecciones básicas que son un logro de la modernidad. De hecho, parecen haber logrado mayor visibilidad aquellos movimientos de minorías que han intentado una igualación de derechos, es decir, un reconocimiento dentro de las normas vigentes las cuales debieron acomodarse a la reivindicación de estos grupos. En este sentido, que el artículo constitucional acerca del matrimonio en Argentina haya modificado la cláusula «hombre y mujer» por «contrayente» parece un ejemplo donde más que parodia hubo una disputa que se dio tanto en el orden cultural como en el institucional. Estos grupos minoritarios tuvieron que jugar el juego que el sistema les proponía, con reglas que suponen que la visibilidad se da sólo a través de un agenciamiento puesto que no hay derechos sin sujeto, $\mathrm{y}$, en algún sentido, quizás no profundamente radical, pudieron modificar el orden de cosas. Más difícil resulta pensar las consecuencias que podría traer aparejadas un aluvión informe e ininteligible de cuerpos abyectos. No porque el Status quo presente una panacea para ellos sino porque la opción de una política des-agenciada puede ser una posibilidad teórica pero una incógnita en la práctica. 


\section{REFERENCIAS BIBLIOGRÁFICAS}

ARIZA, L., 2009: Derecho, saber e identidad indigena. Bogotá: Siglo del hombre editores.

AUSTIN, J. L., 1962: How to do things with words. Oxford: The clarendon Press.

BENTHAM, J., 1932: Bentham's Theory of fictions, compilación realizada por C. K. Ogden. (Versión en español, Teoría de las ficciones, Madrid/Barcelona: Marcial Pons, Ediciones Jurídicas y Sociales, S. A., 2005).

BOCCARDI, F. 2010: «La performatividad en disputa: acerca de detractores y precursores del performativo butleriano», Aesthetika, Revista Internacional sobre Subjetividad, politica y arte, Vol., 5, (2), abril, pp. 24-30.

BRAIDOTTI, R., 1994: Nomadic subjects. New York: Columbia University Press.

BUTLER, J., 1990: Gender trouble. Feminism and the subversión of identity (segunda edición de 1999). (Versión en español, El género en disputa, Paidós: Barcelona, 2007).

—, 1993: Bodies that matter. On the discursive limits of «sex». Nueva York: Routledge.

-, 1997: «Sovereign performatives» en Excitable speech. A politics of the performative, (edición en español, «Soberanía y actos performativos», www. accpar.org/numero4/index.htm).

—, 1998: "Actos performativos y constitución de género: un ensayo sobre fenomenología y teoría feminista». Debate feminista: Año 9, Vol. 18, octubre.

_, 2001: «There is a person here? An interview with Judith Butler» en Breen y Blumenfeld (comps.), International Journal of sexuality and gender Studies, Vol. $6, \mathrm{~N}^{\circ} 1$ y 2 .

—, 2004, «Conflicto de género, teoría feminista y discurso psicoanalítico» en Millán de Benavides, C., Estrada, M. (Ed.), Pensar (en) género. Teoría y práctica para nuevas cartografías del cuerpo. Bogotá: Ed. Pontificia Universidad Javeriana.

BUTLER, J., ARONOWITZ, S., et al 1992: «Discussion» October, V. 61, The identitiy in question, Summer, pp. 108-120.

BUTLER, J., LACLAU, E., ZIZEK, S., 2000: Contingency, hegemony, universality: contemporary dialogues on the left, (ed. en español, Contingencia, hegemonía y universalidad. Diálogos contemporáneos en la izquierda. Bs. As: FCE, 2003).

CLIFFORD, J., 1995, Dilemas de la cultura. Barcelona: Gedisa.

DELEUZE, G., y GUATTARI, F., 1980: Mil plateaux (capitalisme et schizophrenie), (Edición en español, Mil Mesetas. Capitalismo y esquizofrenia. España: Pretextos, 2000).

DERRIDA, J. 1971, «Event, signature, context» (edición en español «Firma, acontecimiento, contexto» en Márgenes de la filosofía. Madrid: Cátedra, 2006).

DWORKIN, R., 1996, Freedom's Law. Cambridge/Massachusetts: Harvard University Press.

—, 1996: Freedom's Law. Cambridge, Massachusetts: Harvard University Press.

ESPOSITO, R., 2007: Terza persona. Politica della vita e filosofía dell'impersonale, (edición en español, Tercera persona. Política de la vida y filosofía de lo 
impersonal. Bs. As.: Amorrortu, 2009).

FELMAN, S. 1983: Don Juan with J. L. Austin, or seduction in two languages. Ithaca: Cornell University Press.

FOUCAULT, M., 1970: L'orden du discours. (ed. en español, El orden del discurso, Madrid: E. de la Piqueta, 1996).

—, 1975: Surveiller et punir, (edición en español, Vigilar y castigar, Bs. As.: Siglo XXI editores, 2002).

- 1978, A verdade e as formas jurídicas, Río de Janeiro, Pontificia Universidade Católica do Río de Janeiro (Edición es español, La verdad y las formas jurídicas. Barcelona: Gedisa, 2003).

—, 1984: Historie de la sexualité 3. Le souci de soi, (edición en español, Historia de la sexualidad 3. La inquietud de sí. España: Siglo XXI Editores, 2003).

—, 2002: L'hermenéutique du sujet. Cours au college de France (1981-1982), (edición en español, La hermenéutica del sujeto. Bs. As: FCE, 2002).

HAAR, M., 1977: «Nietzsche and Metaphysical Language», en ALLISON, D. (comp.) The New Nietzsche: Contemporary Styles of Interpretation. Nueva York: Delta.

HABERMAS, J., 1996: Die einbeziehung des anderen, (ed. en español, La inclusión del otro. Barcelona: Paidós, 1999)

—, 2004: Der gespaltene westen. Kleine politische Schriften, (edición en español, El Occidente escindido. Madrid: Trotta, 2006).

HARAWAY, D., 1995: Ciencia, cyborgs y mujeres. Madrid: Ediciones Cátedra.

IRIGARAY, L., 1974: Speculum de l'autre femme, (edición en castellano, Madrid: Akal, 2007)

JOHNSON, B. 1980: «Poetry an performative language: Mallarmé and Austin», en The critical difference: Essays in the contemporary rhetoric on reading. Baltimore: Johns Hopkins University Press.

KYMLICKA, W., 1995: Multicultural citizenship, (ed. en español, Ciudadanía multicultural. Barcelona: Paidós, 1995)

LACLAU, E. y MOUFFE, Ch. 1985: Hegemony and socialist strategy, $2^{\circ}$ edición, (edición en español, Hegemonía y estrategia socialista. Hacia una radicalización de la democracia. Bs. As.: FCE, 2004).

LACLAU, E., 2005: On populist reason, (edición en español, La razón populista. Bs As.: FCE, 2008).

LAZZARATO, M. 2006a: Políticas del acontecimiento. Bs. As.: Tinta Limón.

—, 2000: «Del biopoder a la biopolítica», Multitudes, $\mathrm{N}^{\circ} 1$, marzo.

—, 2006b: Biopolítica. Estrategias de gestión y agenciamientos de creación. Bogotá: Ediciones de la fundación Universidad Central-IESCO.

LOPEZ HERNANDEZ, J., 2005: «Clasificación de las normas jurídicas como enunciados de actos ilocutivos», en Anuario de Derechos Humanos: $N^{\circ} 6$, Madrid, pp. 455-509.

MAC INTYRE, A., 1981: After virtue, London, Duckworth.

MACKINNON, C., 1993: Only Words. USA: Harvard University Press.

MOUFFE, Ch., 2007: En torno a lo político. Buenos Aires: FCE.

NEGRI, T., y HARDT, M., 2000: Empire. Cambridge Massachusetts: Harvard University Press, 
Sujetos de derecho...

PALMA, D., 2010: Borges.com. La ficción de la filosofía, la política y los medios. Buenos Aires: Biblos.

POTTAGE, A., 2004: «Introduction: the fabrication of persons and things» en Pottage, A., Mundy, M., Law, Antrophology, and the constitution of the social. Making persons and things. Cambridge: Cambridge Univ. Press.

PRATT, M. L. 1977: A speech act theory of literary discourse. Indiana: Indiana University Press.

PRECIADO, B., 2002: Manifiesto contra-sexual. Madrid: Opera Prima.

RAWLS, J., 1971: A Theory of justice. Massachusetts: Harvard University Press Cambridge (Ed. revisada 1999).

SABSAY, L., 2011: Fronteras sexuales. Espacio urbano, cuerpos y ciudadanía. España: Paidós.

SANDEL, M., 1982: Liberalism and the limits of justice. Cambridge: Cambridge University Press.

SEARLE, J., 1969: Speech Acts. An essay in the philosophy of language. Cambridge: Cambridge University Press.

SPIVAK, G., 1977: "Can the subalterns speak» en Aschcroft, Grffiths y Tiffin. The post-colonial studies reader. London/New York: Routledge.

STAVRAKAKIS, Y. 2007: The lacanian left. Psychoanalysis, Theory, Politics, (edición en español, La izquierda lacaniana. Psicoanálisis, Teoría, Política. Bs. As.: FCE, 2010).

TAYLOR, Ch., 1990: Sources of the Self. Cambridge: Cambridge University Press.

—, 1992: Multiculturalism and «The political of recognition», edición en español, El multiculturalismo y «La política del reconocimiento». México: Fondo de Cultura Económica, 1993.

TEUBNER, G., 1997: «The king's many bodies: the self deconstruction of Law's hierarchy». Law and society Review: 31 (4), 763-787.

VALVERDE, M., 2003: Law's Dream of a Common Knowledge. Princeton: Princeton University

VAN KRIEKEN, R. 2006: «Law's autonomy in Action: Anthropology and History in Court», Social and legal studies 15 (4) 574-590

VIRNO, P. 2004: Quando il verbo si fa carne, (edición en español, Cuando el verbo se hace carne. Argentina: Tinta Limón, 2004).

WALZER, M. 1983: Spheres of justice. New York: Basic Books.

WITTIG, M., 1992: The straight mind and other essays (edición en español, El pensamiento heterosexual y otros ensayos. Barcelona y Madrid: Egales, 2006).

Dante Augusto Palma es Doctor en Ciencia Política por la Universidad de San Martín (Argentina) y Profesor de Filosofía por la Universidad de Buenos Aires (Argentina).

Linea de investigación

Investiga el carácter performativo del lenguaje del derecho y el modo en que éste repercute al interior del debate acerca de la protección de las minorías. 
Publicaciones recientes

El Adversario (editorial Biblos, 2012) y su tesis de doctorado El sujeto de derecho en el siglo XXI. Ficción, lenguaje performativo e identidades estratégicas de las minorías (Editorial UNIPE, Bs As, La Plata, en prensa).

Dirección electrónica: danteaugustopalma@yahoo.com.ar 